\title{
Selective light transmission as a leading innovation for solar swimming pool covers
}

\author{
Rémi Wachéa,b, Tim Fielder $^{\mathrm{b}}$, Will E.C. Dickinson ${ }^{\mathrm{a}, \mathrm{b}}$, Joe L. Hall ${ }^{\mathrm{a}, \mathrm{b}}$, Peter Adlington ${ }^{\mathrm{b}}$, Stephen \\ J. Sweeney ${ }^{\mathrm{a}}$, Steven K. Clowes, \\ ${ }^{a}$ Department of Physics, University of Surrey, Guildford GU2 7XH, UK \\ ${ }^{b}$ Plastipack Ltd, Wainwright House, 4 Wainwright Close, Churchfields Industrial Estate, Saint Leonards-on-sea TN38 \\ 9PP, UK
}

\begin{abstract}
An innovative, extrudable material with the ability to filter the sun's energy has been developed for the mass manufacture of high performance swimming pool covers. Solar radiation in the visible spectrum $(<750 \mathrm{~nm})$ is absorbed by the material so that minimal visible light enters the pool water which inhibits photosynthesis to prevent algae growth. Furthermore, the material has high transmission properties in the near infrared that can be efficiently absorbed by the water allowing for a higher temperature increase compared to a standard non-selective opaque cover. We have developed a model to enable the cover efficiency to convert solar energy to heat a swimming pool, calculated based on the wavelength dependent absorption and transmission properties of the cover. We have validated this model using dedicated full-scale test-facility. Our results demonstrate that a selective transmission cover can increase the absolute heating efficiencies by approximately $12 \%$ compared to the fully opaque equivalent.
\end{abstract}

Keywords: Solar Energy, Outdoor swimming pool, Pool cover efficiency model, Experimental validation, Solar thermal systems

\section{Introduction}

Private swimming pool ownership continues to be growing market as it has for decades. In both California and Florida alone, there are over 2 million in-ground swimming pools with the number of residential pools in the United States estimated to be above 8 million units APSP (2015)). This growth in residential pools is also seen in other countries, including Australia where there are 800,000 privately owned pools. The construction cost required to satisfy this growing demand for new pools has great economic and resource cost. However, the initial building cost of a pool represents only a fraction of the total cost involved in the running and maintenance. The main resource costs are from water, chemicals and energy for heating. Loss of water due to evaporation can represent as much as 60 cubic meters a year for a standard size $8 \mathrm{~m} \times 4 \mathrm{~m}$ pool. Chemicals used for sanitation and algae prevention must be topped up constantly as they are consumed by the presence of debris, nutrients, algae and UV photolysis.

\footnotetext{
${ }^{*}$ Corresponding author

Email address: s.clowes@surrey.ac.uk (Steven K. Clowes) 
Heat is required to provide a comfortable swimming environment or to extend the swimming pool season during the colder months.

Covering a pool reduces the consumption of these important resources considerably. A bubble swimming pool cover eliminates evaporation by on average $95 \%($ Muleta $(2015))$, as well as prevents debris from entering the water and absorbs the UV that prevents the photolysis of chlorine. It allows for heat gain through solar energy absorption and acts as an insulating barrier to reduce heat loss(Yellott (1963)). Therefore, even the simplest product such as a polyethylene bubble film provides significant benefits(DOE (2000)). Until recently such pool covers were available in different colours mainly to suit different aesthetic tastes. Covers were either opaque or transparent products, which provide specific functionalities. Opaque products cut all the solar radiation, hence they prevent the photosynthesis of algae, making them effective winter covers. With these covers, even without adding chemicals, the water remains clear all through the winter, reducing maintenance spent in spring to service the pool. However, because all the solar energy in an opaque cover is absorbed these covers are less efficient in heating the water. On the other hand, a transparent cover allows solar radiation to penetrate the water, hence the energy is directly absorbed by the water and walls of the pool leading to a temperature increase higher than an opaque cover. These covers are effective at reducing heating costs, as well as extending the swimming pool season in spring and autumn. However they come with an unfortunate drawback, as they do not inhibit algae growth, the chemical balance must be maintained at all times to avoid an algae bloom.

In section 2, we describe the optimal cover for preventing algae growth while maximising solar heating, and the development of this selective transmission cover design is described in Section 3. A lab based experiment which measures the algae preventative properties of the covers is provided in Section 4. Using a dedicated, purpose-built test-facility, the daily thermal cycles of pools with transparent, opaque and selective transmission properties are measured and discussed in Section 5. In Section 6, we present a simple thermal model to predict the cover ability to convert solar energy into heating the pool, and the model is validated in Section 7 using the test-facility measurements. Finally, our conclusions are presented in Section 8. 


\section{Nomenclature}

\begin{tabular}{|c|c|}
\hline$\overline{A_{\mathrm{p}}}$ & pool surface area $\left(\mathrm{m}^{2}\right)$ \\
\hline$C_{\mathrm{p}}$ & specific heat capacity of water $\left(4.182 \mathrm{kJkg}^{-1} \mathrm{~K}^{-1}\right)$ \\
\hline$C_{\mathrm{c}}$ & specific heat capacity of cover $\left(\mathrm{kJkg}^{-1} \mathrm{~K}^{-1}\right)$ \\
\hline$\Delta T_{\mathrm{p}}$ & pool temperature change between 9 am and 7 pm $(\mathrm{K})$ \\
\hline$\Delta T_{\mathrm{c}}$ & cover temperature change between 9 am and $7 \mathrm{pm}(\mathrm{K})$ \\
\hline I & solar irradiance $\left(\mathrm{Wm}^{-2}\right)$ \\
\hline$P_{\mathrm{v}, \mathrm{sat}}\left(T_{\mathrm{p}}\right)$ & saturation vapour pressure of air at pool temperature $(\mathrm{Pa})$ \\
\hline$P_{\mathrm{v}, \mathrm{a}}$ & vapour pressure in ambient air $(\mathrm{Pa})$ \\
\hline$Q_{\text {conv }}$ & rate of convection heat loss $(\mathrm{W})$ \\
\hline$Q_{\text {evap }}$ & rate of evaporative heat loss $(\mathrm{W})$ \\
\hline$Q_{\text {gain }}$ & rate of heat gain of pool $(\mathrm{W})$ \\
\hline$Q_{\text {losses }}$ & rate of heat losses of pool (W) \\
\hline$Q_{\text {rad }}$ & rate of radiative heat loss $(\mathrm{W})$ \\
\hline$R^{2}$ & coefficient of determination $(-)$ \\
\hline$T_{(<750)}$ & fraction of cover transmission of light below $750 \mathrm{~nm}(-)$ \\
\hline$T_{(>750)}$ & fraction of cover transmission of light above $750 \mathrm{~nm} \mathrm{(-)}$ \\
\hline$T_{\mathrm{c}}$ & temperature of cover $(\mathrm{K})$ \\
\hline$T_{\mathrm{p}}$ & temperature of pool $(\mathrm{K})$ \\
\hline$T_{\text {sky }}$ & effective sky temperature $(\mathrm{K})$ \\
\hline$V_{\mathrm{c}}$ & volume of cover $\left(\mathrm{m}^{3}\right)$ \\
\hline$V_{\mathrm{p}}$ & volume of pool $\left(\mathrm{m}^{3}\right)$ \\
\hline$\alpha_{\mathrm{c}}$ & absorptance of cover (-) \\
\hline$\alpha_{\mathrm{p}}$ & absorptance of pool (-) \\
\hline$\beta$ & fraction of energy aborbed by cover which is transferred to the pool (-) \\
\hline$h_{\text {conv }}$ & convection heat transfer coefficient $\left(\mathrm{Wm}^{-1} \mathrm{~K}^{-1}\right)$ \\
\hline$h_{\text {evap }}$ & evaporative heat transfer coefficient $\left(\mathrm{Wm}^{-1} \mathrm{~K}^{-1}\right)$ \\
\hline$\alpha_{\mathrm{p}}^{*}$ & reduced absoprtance of pool due to cover (-) \\
\hline$\epsilon_{\mathrm{W}}$ & emissivity of water (-) \\
\hline$\epsilon_{\mathrm{c}}$ & emissivity of cover (-) \\
\hline$\eta$ & absolute pool cover effciency (-) \\
\hline$\rho_{\mathrm{c}}$ & density of cover $\left(\mathrm{kgm}^{-3}\right)$ \\
\hline$\rho$ & density of water $\left(99.8 \mathrm{kgm}^{-3}\right.$ at $\left.25^{\circ} \mathrm{C}\right)$ \\
\hline$\sigma$ & Stefan-Boltzmann constant $\left(5.67 \times 10^{-8} \mathrm{Wm}^{-2} \mathrm{~K}^{-4}\right)$ \\
\hline$w$ & Wind speed $\left(\mathrm{ms}^{-1}\right)$ \\
\hline
\end{tabular}

\section{Optimal cover design}

The sun radiates almost as a blackbody, which after atmospheric absorption results in the radiation spectrum (ASTM (2012)) at sea level as depicted on Fig. 1. More than $95 \%$ of the solar energy at sea level is contained in the spectral region between $200 \mathrm{~nm}$ and $2500 \mathrm{~nm}$, where ultra-violet represents about $10 \%$, the visible about $50 \%$ and the infrared nearly $40 \%$ of the total received energy.

Plants, much like the human eye, have evolved to be sensitive to only part of this spectrum corresponding to the visible region where the solar radiation is at its most intense. They use 


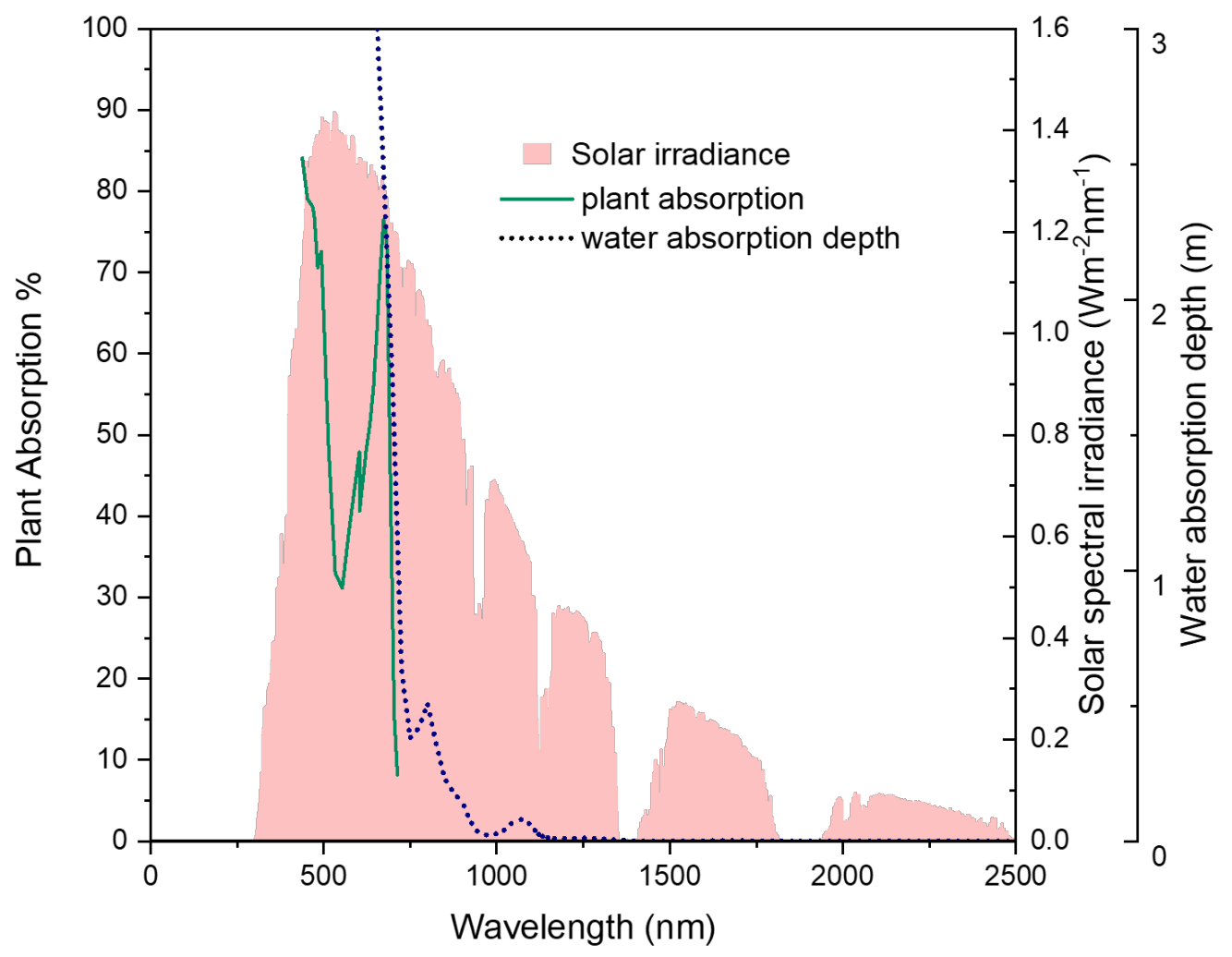

Figure 1: Solar irradiation spectra at sea-level, typical absorption spectra of plants, and absorption depth of water. 
different pigments to absorb the light necessary for their growth (Duysens (1964); Emerson and Lewis (1943); Aparicio et al. (1974)). The most common of which are chlorophyll pigments responsible for the green colour of leaves. A typical absorption spectrum of plants(Emerson and Lewis (1943)) is represented on Fig. 1. The process of photosynthesis uses the energy of photons that are absorbed by the different pigments and converted for the photosystem I and II to an energy level corresponding of maximum $720 \mathrm{~nm}$ (Duysens (1964); Kirk (1994)). Algae are adaptive organisms able to change their pigmentation to accommodate the light received at a certain depth(Kirk (1994)). In order to block photosynthesis of algae, the most effective method is to remove all radiations with wavelengths that can be potentially absorbed by algae pigments. This corresponds to a range comprised between 400 to $720 \mathrm{~nm}$ (Eckardt (2012); Goedheer (1969); Yokono et al (2011)). Hence, an algae inhibiting cover must prevent the wavelengths between 400 to $720 \mathrm{~nm}$ from entering the water.

Direct transmission of solar energy is the most efficient method to increase water temperature as the energy can be absorbed directly by the water and walls of the pool. Heating via the absorption of light by the cover contributes to a lesser extent, as heat can be lost to the surrounding air through convection and radiative emission. For a cover to inhibit algae growth, it will need to absorb wavelengths between 400 to $720 \mathrm{~nm}$. Radiation above $720 \mathrm{~nm}$ will not promote algae growth, hence, the infrared would contribute most efficiently to heating the pool water if they are transmitted by the cover. Assuming all this energy could be absorbed by the water, this would represent almost half of the solar radiation. In fact, the absorption coefficient of water(Hale and Querry (1973)), as shown in Fig. 1, is very high in the infrared. This indicates that these wavelengths are efficiently absorbed by water and all the corresponding energy will be fully harvested. In contrast, in the visible region the absorption depth is much higher than $10 \mathrm{~m}$ and it would require depths much greater than the few meters of a typical pool to achieve a noticeable heating effect through absorption by the water. Hence, the absorption of all the visible light is dominated by the absorption of the walls of the pool. Ultra-violet light is responsible for the photolysis of chlorine(Nowell (1992)) and like visible light is poorly absorbed by the water. Transmission of ultra-violet should be avoided by preferentially absorption by the cover. Consequently, an ideal cover, which would inhibit algae growth and maximise solar heating, would be opaque below $720 \mathrm{~nm}$ and transparent above this wavelength.

\section{Development of the selective transmission cover}

To achieve the desired wavelength selective transmission of the cover, we adopted an approach to select a combination of additives that are transparent in the near infrared and absorb different wavelengths in the visible resulting in a combined absorption band between the desired wavelengths from $200 \mathrm{~nm}$ to $720 \mathrm{~nm}$. The additives were also selected to be stable in a harsh pool environment with a combined resistance to ultra-violet, chlorine and heat. Our preliminary studies led to the selection of three pigments. The absorption spectra of these pigments suspended in IPA is presented in Fig. 2

A blend of these pigments was combined into a masterbatch that dilutes the polyethylene material used to manufacture the cover. A bubble swimming pool polyethylene cover is formed using a dual layer extrusion process where one of the layer is sucked on a forming roller with the shapes of the bubble and laminated to a second flat layer. In order to maximize the heat conducted from the cover to the water, the master batch was introduced and diluted in the feeder corresponding to the bottom layer of the cover while the composition for the top layer has been maintained translucent. For an opaque cover the simplest, most stable and cheapest additive 


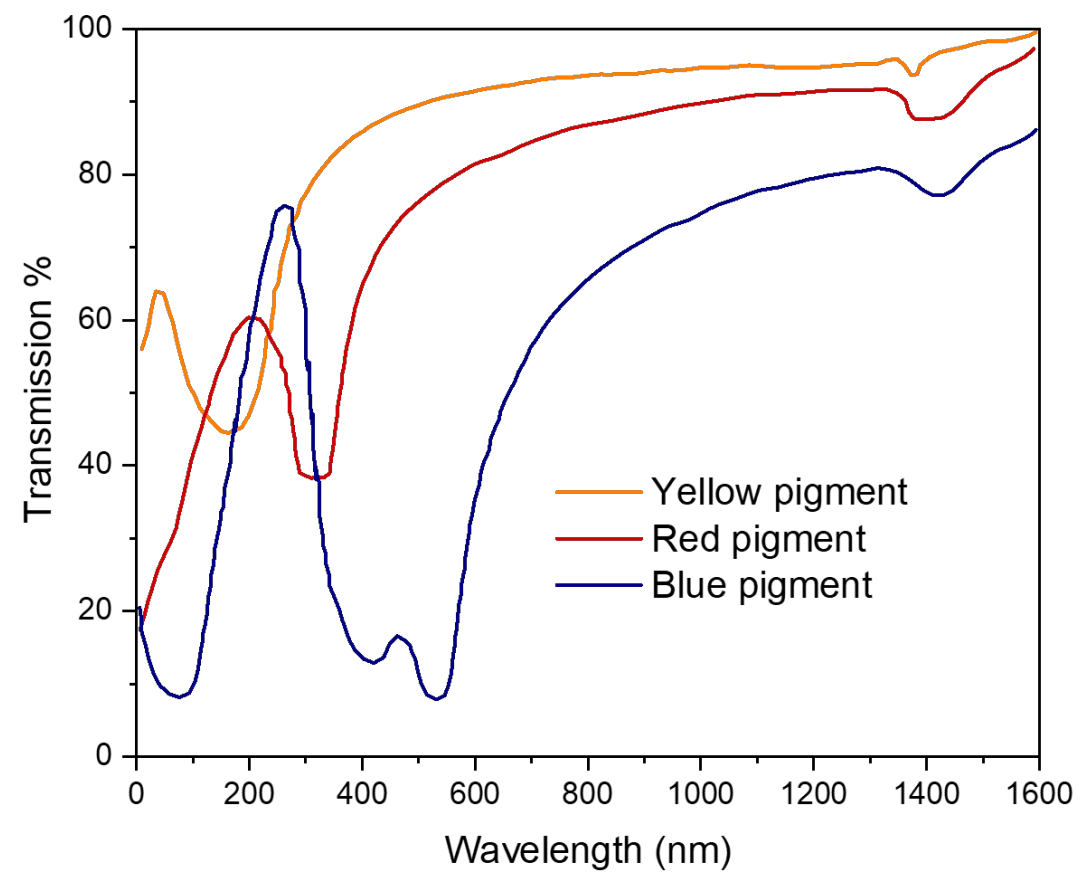

Figure 2: Transmission spectra of selected pigments suspended in IPA

route is to use the pigment carbon black, which has virtually non-selective $100 \%$ absorbance across the visible and infrared regions. For this study, an opaque cover was used that had a carbon black lower layer and a light-blue upper layer. Following a series of trials for the selective transmission cover, the concentration of the different pigments masterbatch and the dilution ratio were adjusted to produce the minimal transmission of light in the visible and ultra-violet. A visual comparison of the transparent, opaque and selective transmission covers is shown in Fig. 3. The measured reflection, transmission and absorption spectra of the final extruded product was performed using a Cary 5000 UV-Vis-NIR spectrometer and is shown in Fig. 4 which is compared to transparent and opaque covers. The transparent cover material is actually semi-transparent with a maximum transmission of around $70 \%$ which is due to the crystalline properties of the polyethylene material. The transparency of the selective transmission cover is maximised by keeping the additives required for stabilisation to the minimum. This new material exhibits almost a full absorption of visible light apart from a small window at $510 \mathrm{~nm}$ with a transmission less than $4 \%$ at its peak. The transmission increases sharply above $720 \mathrm{~nm}$ to reach almost $80 \%$ of the light transmission of the transparent product at $1600 \mathrm{~nm}$. 


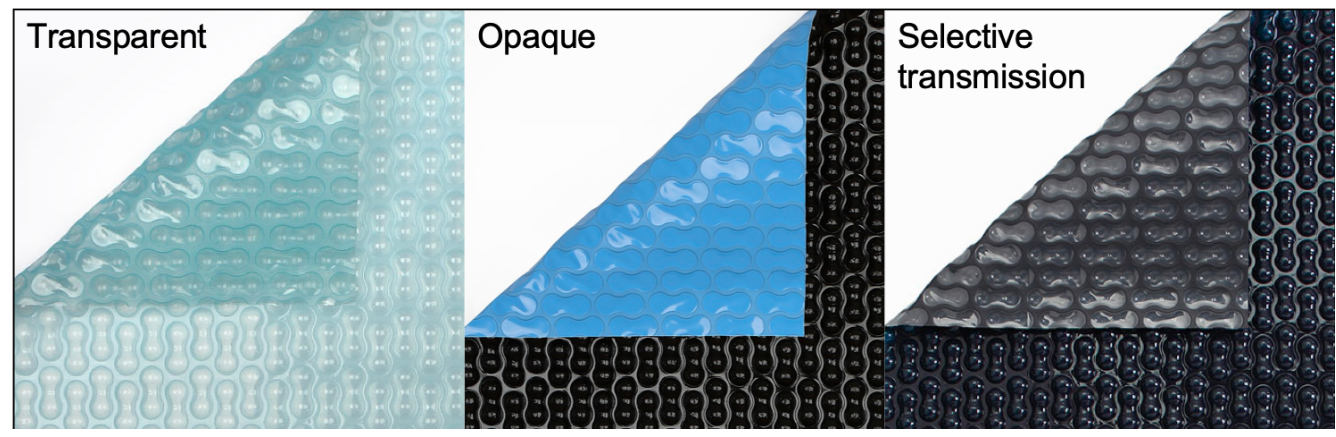

Figure 3: Visual comparison of the transparent, opaque and selective transmission bubble covers that were used in this study. The folded corner shows the top surface of the cover.

\section{Algae testing}

The ability to inhibit algae growth was tested in a lab scale controlled environment. The test consisted of growing a commercially available type of algae (Chlorophyta Scenedesmus Quadricauda) that was diluted in a 3\% sodium alginate solution. This viscous mixture was placed in an open syringe and gravity allows for droplets to evenly form and fall into a $2 \%$ calcium chloride bath underneath. This causes the alginate containing the algae to precipitate in homogeneous jelly spheres. Therefore, by counting the number of spheres, the same amount of algae can be disposed in several identical Bijou bottles containing water. The Bijou bottles are then sealed, wrapped with the materials to be tested and exposed to a light source at a set distance. Because the light spectrum is not a perfect match to the solar spectrum, the test has also been carried out with the sample exposed to natural light just behind a window. It should be noted that both the glass Bijou bottle and window will partly absorb both visible and IR regions. The respiration of algae, which is an indication of photosynthesis, is monitored by the $\mathrm{pH}$ of the solution as the consumption of dissolved carbon dioxide changes the acidity of the solution. The results of the experiment are summarized in Table 2. For Trial A, the case for water alone, there is only a slight increase in the $\mathrm{pH}$ level. In the case where algae is added and no cover is used (Trial B), there is a significant increase in the $\mathrm{pH}$ level to 9.2. Both the opaque (Trial $\mathrm{C}$ ) and selective transmission (Trial D) covers prevent an increase in the $\mathrm{pH}$ level, which indicates that both are effective for the prevention of algae growth.

\begin{tabular}{clc}
\hline Trial & Bijou bottle content & pH (natural light) \\
\hline A & control (no algae) & 7.8 \\
B & algae control & 9.2 \\
C & algae with fully opaque cover & 7.6 \\
D & algae with selective transmission cover & 7.6 \\
\hline
\end{tabular}

Table 2: Measurement of $\mathrm{pH}$ of Bijou bottles containing A water, B water with algae, $\mathrm{C}$ water with algae and surrounded by fully opaque cover, and $\mathrm{D}$ water with algae and a surrounded by new cover material 


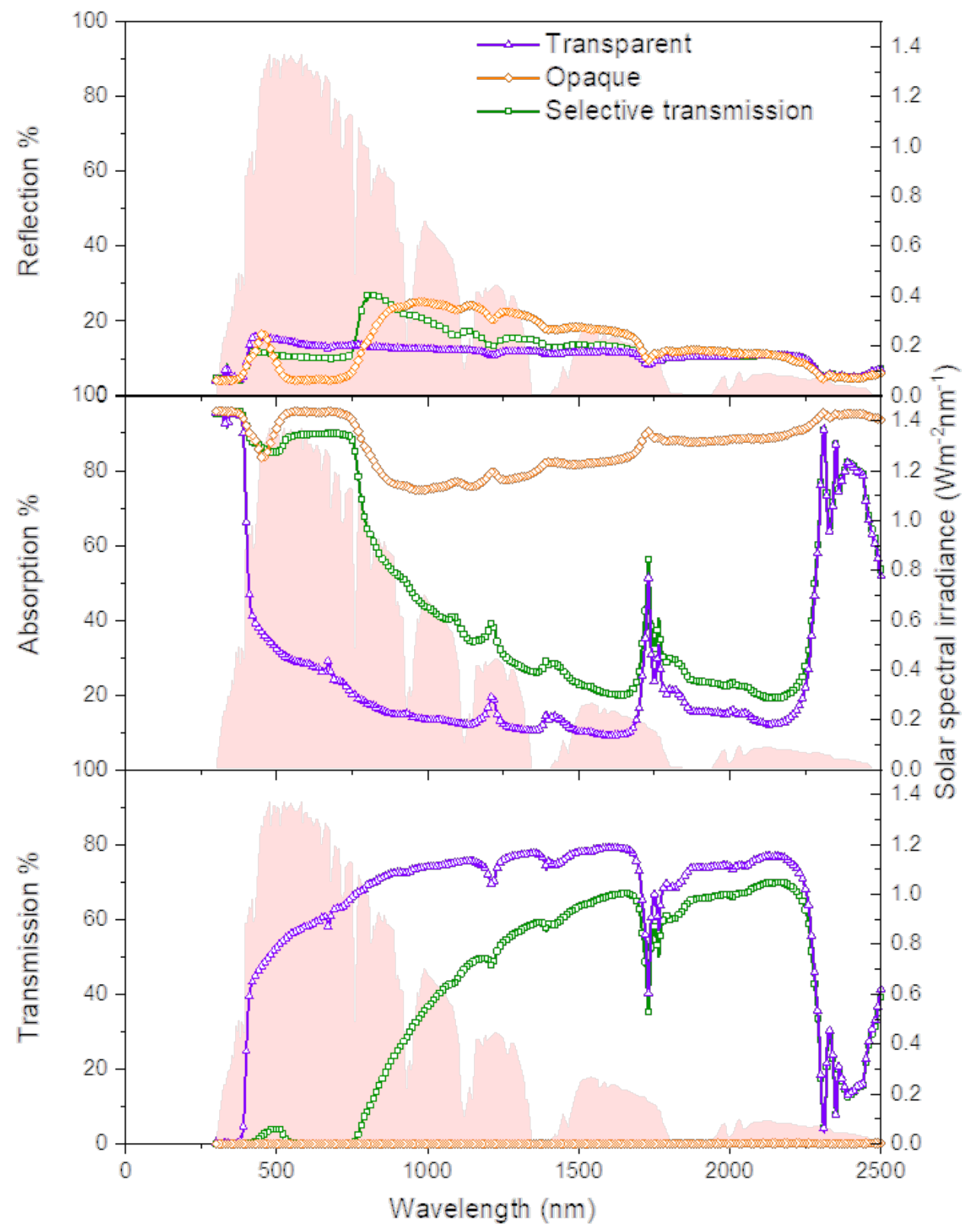

8

Figure 4: Reflection, transmission and absorption spectra of the transparent, opaque and selective transmission covers that were used in the study. Also shown is the solar spectral irradiance at sea level. 


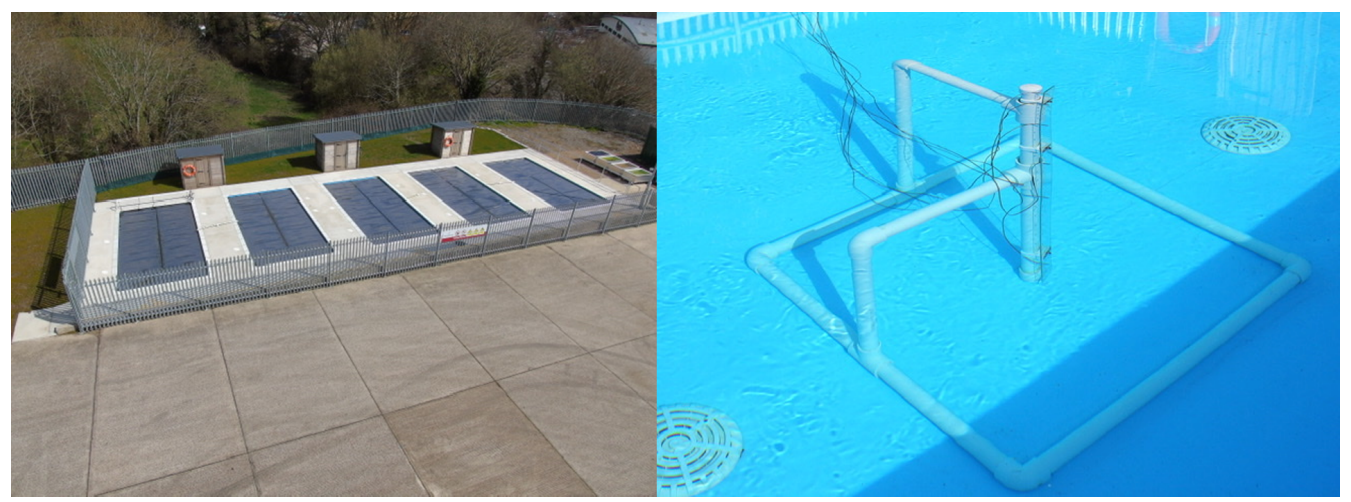

Figure 5: Left: aerial View of test pool facility (different covers shown as were used in this experiment). Right: submerged stand for thermocouple mounting.

\section{Test-pool facility experiment}

An advanced study of cover solar heating performances was tested on full scale pools using a purpose built test facility comprising of five unheated pools measuring $8.0 \mathrm{~m} \times 4.0 \mathrm{~m}$ with a depth of $1.3 \mathrm{~m}$, Fig. 5. The pools were built in a location chosen because of the absence of buildings and tall trees so that it is not necessary to account for shadowing of the pools as this only occurs at sunrise and sunset during low solar irradiance. Three of the five pools were covered with transparent, opaque and a selective transmission covers, with one of the pools uncovered. Testing took place during the summer of 2018 in the South East of the United Kingdom (latitude $51^{\circ}$ ), over the period between the $16^{\text {th }}$ of June and the $3^{\text {rd }}$ of July. The pool temperatures were monitored using six thermocouples in each pool positioned on a central post at depths of 2, 11, 20, 30, 50 and $130 \mathrm{~cm}$ below the cover, Fig. 5. The filtration circulation pumps have a daily cycle of being switched on between $10 \mathrm{am}$ to $4 \mathrm{pm}$ and between $10 \mathrm{pm}$ to midnight. Measurements were logged every five minutes, including solar radiation from a Campbell Scientific four-component net radiation sensor and full environmental data from a local weather station(IEASTSUS47 (2018)). The average high and low temperatures during this period were $23.9^{\circ} \mathrm{C}$ and $12.8^{\circ} \mathrm{C}$, respectively, with an average daily solar irradiance of $6.37 \mathrm{kWh} / \mathrm{m}^{2}$.

A typical daily cycle of the pool temperature profile for the full set of thermocouples for each type of cover is shown in Fig. 6(18th June). It can be seen that the temperature reading directly below the cover is very sensitive to the temperature of the cover, particularly when the circulation pumps are inactive. To account for this temperature profile, a true average pool temperature was extracted using a linear interpolation of thermocouple readings. The averages are shown for this testing period in Fig. 77, which also includes the total solar radiation incident on the surface of each pool for each day as measured by the radiation sensor. We have defined the the daytime increase and nighttime decrease as between the times 9 am and 7 pm, as shown in Fig. 6. The average daytime and nighttime temperature changes over the whole testing period are shown in Table 3 Due to a sensor acquisition malfunction for the pool with the transparent cover, the cover was removed and no temperatures were recorded for days 6-10 of the testing period. 


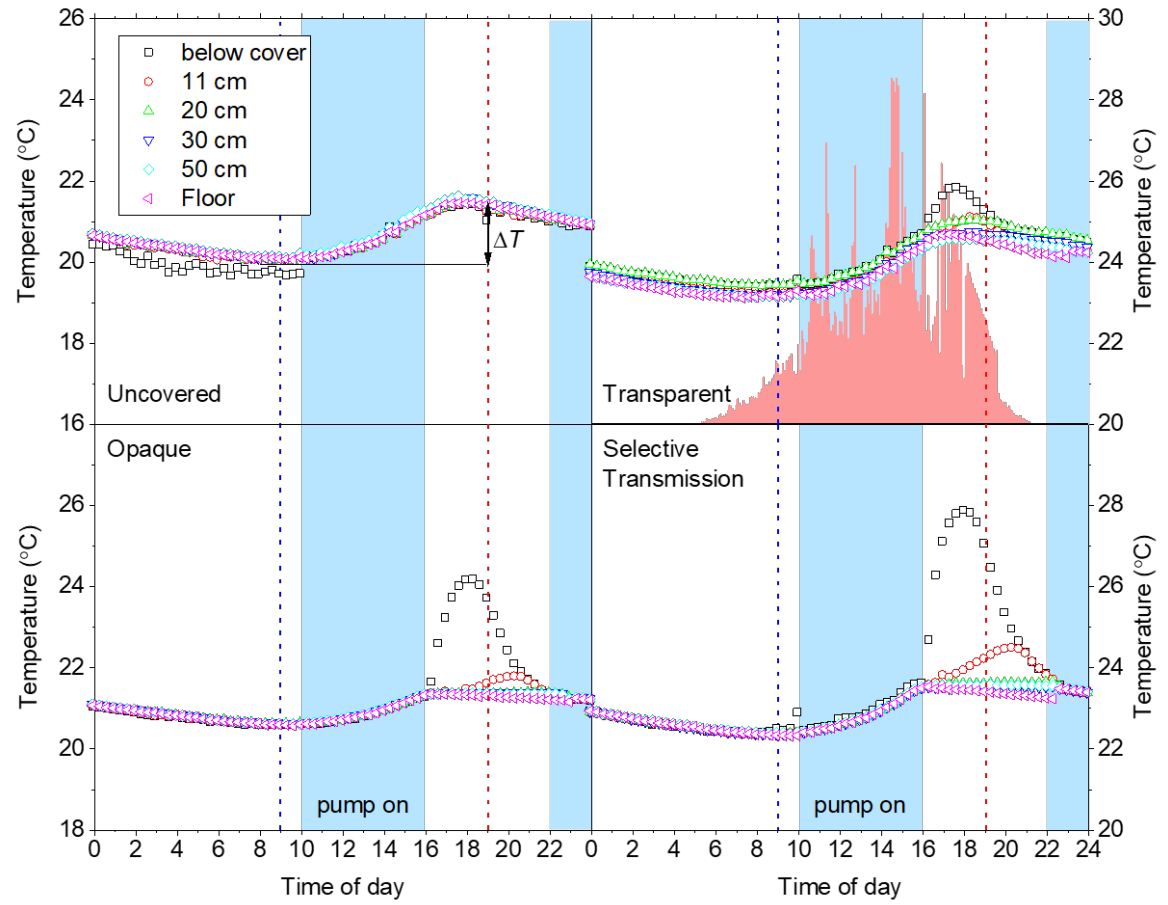

Figure 6: Recorded thermocouple temperatures in the full-scale test pool facility on 18th June 2017. The blue and red dotted lines indicate times when average low and high temperatures were recorded to determine temperature gain due to solar heating. The full scale of all four plots is $10^{\circ} \mathrm{C}$ to enable comparison of temperature change. The blue shaded areas indicate when water circulation pumps were active. Also shown in the top-right pane is that profile of the solar irradiance, where the integrated value $E_{\text {sol }}$ between 9 am and $7 \mathrm{pm}$ is $4.89 \mathrm{kWh} / \mathrm{m}^{2}$. 


\begin{tabular}{c|c|c|c} 
Cover & Day $\Delta T_{\mathrm{p}}$ & Night $\Delta T_{\mathrm{p}}$ & Daily $\Delta T_{\mathrm{p}}$ \\
\hline Uncovered (control) & $+0.98 \pm 0.28$ & $-0.90 \pm 0.44$ & $+0.09 \pm 0.52$ \\
Transparent & $+1.09 \pm 0.27$ & $-0.43 \pm 0.20$ & $+0.66 \pm 0.33$ \\
Opaque & $+0.70 \pm 0.15$ & $-0.50 \pm 0.22$ & $+0.20 \pm 0.27$ \\
Selective Transmission & $+1.02 \pm 0.19$ & $-0.61 \pm 0.27$ & $+0.40 \pm 0.32$
\end{tabular}

Table 3: Average daily temperature rise and fall $\left({ }^{\circ} \mathrm{C}\right)$ for in-ground swimming pools with transparent, opaque and selective transmission covers in comparison to an uncovered control pool. Averages taken over the period of $15^{\text {th }}$ of June to $2^{\text {nd }}$ July 2018 in the South East of the United Kingdom. Day and night are as defined between 9 am and 7 pm.

\section{Cover solar heating efficiency model}

The data of the average daytime temperature gains and nighttime losses for the two trials given in Table 3 indicate a high degree of variability in the day-to-day temperature change. Therefore, it does not provide a meaningful measure of the cover properties independent of changes in the environmental conditions and more importantly region. However, it is possible to obtain solar heating efficiencies for the covers, that are independent of local weather conditions, by considering the energy balance of the pool thermal system. This cover efficiency is dependent only on the wavelength dependent optical properties of the cover.

A simplified description of influence of the cover is shown in Fig. 8 which indicates the dominant heat transfer processes; ignoring convection from the pool surface and conduction loss through the pool walls(Woolley et al (2011)). For the uncovered pool and the pool with the transparent cover, the visible (1) and the near-IR below $750 \mathrm{~nm}$ (2) solar radiation is transmitted into the pool and absorbed by the walls which is then transferred into the pool through conduction and convection (5). For the uncovered pool the dominant heat loss is through evaporation (4) which is prevented in the presence of a cover. It is important to note that the absorption of the water in the pool is wavelength dependent, Fig. 1. such that the infrared solar radiation above $750 \mathrm{~nm}$ (3) will be absorbed within the upper layer of the pool water. Transparent and selective transmission covers allow the infrared solar radiation to penetrate the cover which is directly absorbed water beneath the cover. However, all pool covers will absorb some proportion of the solar energy. This can then be emitted as thermal radiation into the pool (7), but with a significant proportion of this energy lost by emission from the cover back into the atmosphere (6). For the opaque cover, this thermal emission will be dominant heating mechanism. However in the case of the selective transmission cover, it can also directly heat the water by absorption of the solar infrared which gives it an improved heating efficiency over the opaque cover. This cover will also emit more thermal radiation back into the atmosphere compared to a transparent cover. In all cases, a proportion of solar radiation will be reflected back into the atmosphere (8). Here we present a model in which the energy balance of the pool and the cover are treated separately.

The daytime pool energy balance is described by the rate equation

$$
C_{\mathrm{p}} \rho V_{\mathrm{p}} \frac{d T_{\mathrm{p}}}{d t}=Q_{\text {gain }}-Q_{\text {losses }}
$$

The heat losses for an uncovered pool are dominated by evaporation and radiation, as convection and conduction through the pool walls contribute only a few percent to the total losses(Woolley et al (2011)), so that,

$$
Q_{\text {losses }}=Q_{\text {rad }}+Q_{\text {evap }}
$$




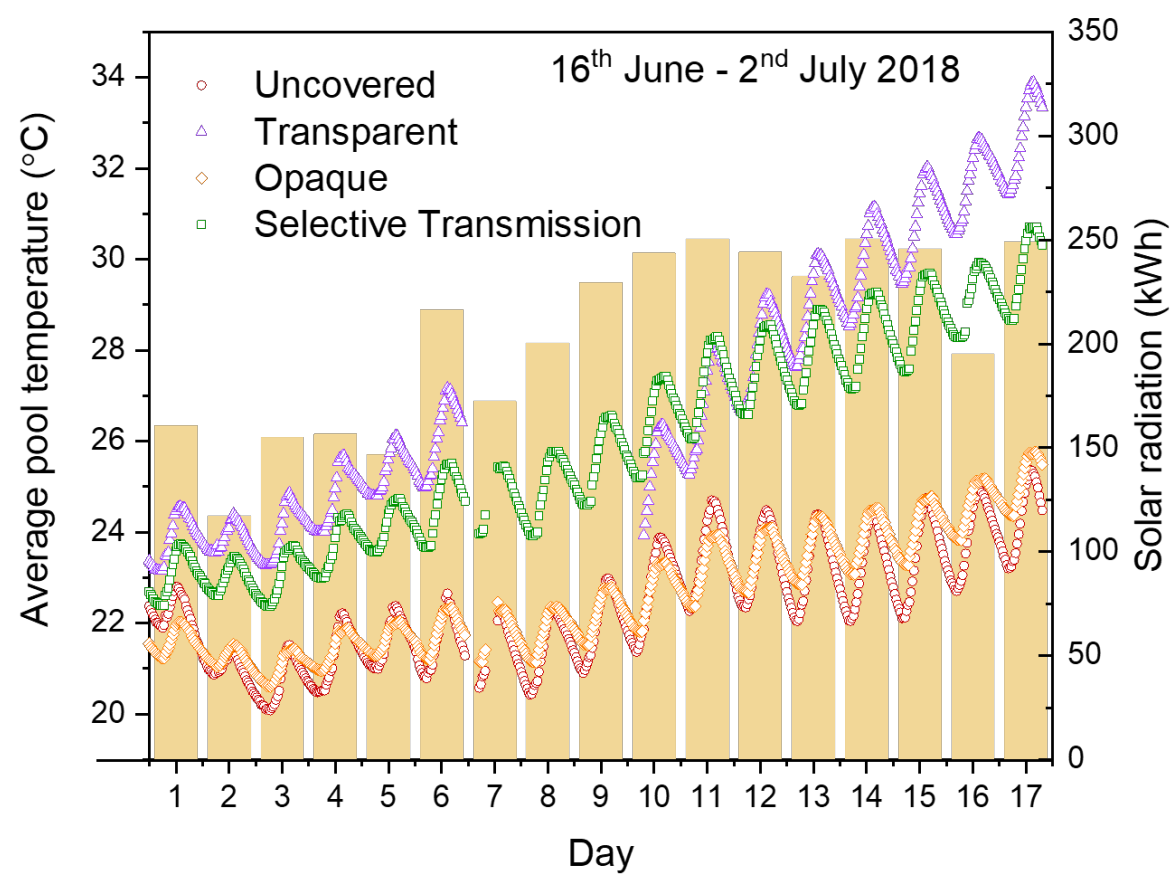

Figure 7: Average pool water temperatures with three different covers during $16^{\text {th }}$ June to $2^{\text {nd }}$ July 2018 using the full scale test pool facility in the South East of the United Kingdom. Also shown is the total daily solar radiation incident on each individual pool.

Evaporative losses are prevented by the presence of a cover. However for the uncovered pool they would be strongly dependent on the wind velocity as described by(Sweers (1976))

$$
Q_{\text {evap }}=A_{p} h_{\text {evap }}\left[P_{\mathrm{v}, \mathrm{sat}}\left(T_{\mathrm{p}}\right)-P_{\mathrm{v}, \mathrm{a}}\right] \quad h_{\mathrm{evap}}=0.036+0.025 w,
$$

where $h_{\text {evap }}$ is the evaporative heat transfer coefficient(Ruiz and Martínez (2010)). The radiative losses for an uncovered pool are,

$$
Q_{\mathrm{rad}}=A_{p} \epsilon_{w} \sigma\left(T_{p}^{4}-T_{s k y}^{4}\right)
$$

where $T_{\text {sky }}$ is the effective sky temperature(Walton $\left.(1983)\right)$. For the unheated pools used in this study, the only energy gain is through solar heating so that for an uncovered pool $Q_{\text {gain }}=$ $Q_{\text {sol }}$ where the solar energy directly absorbed by the water and the floor and sidewalls of the pool(Hahne and Kübler (1994); Ruiz and Martínez (2010); Woolley et al (2011); Buonomano et al. (2015); Lugo et al. (2019)). This solar energy gain is proportional to this total absorptance of the pool and solar irradiance such that

$$
Q_{\text {gain }}=Q_{\text {sol }}=A_{\mathrm{p}} \alpha_{\mathrm{p}} I
$$




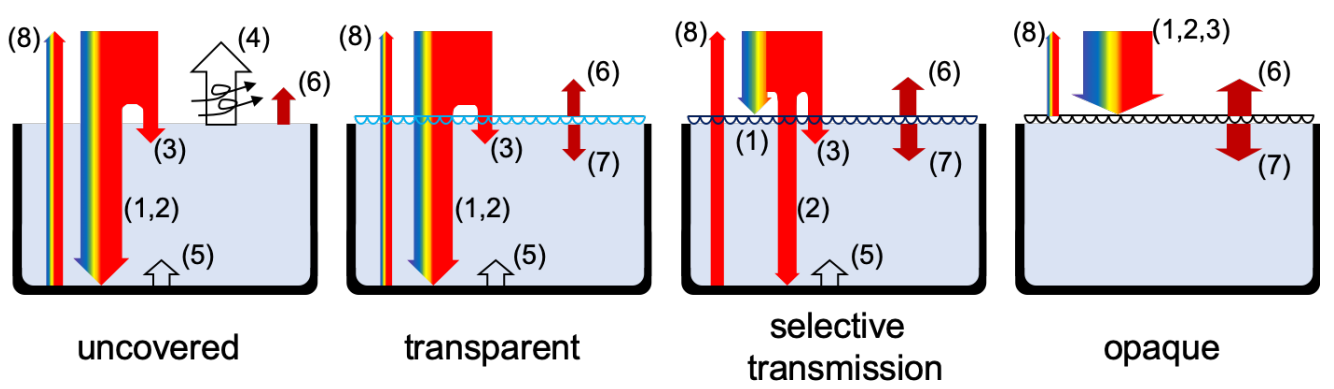

Figure 8: Dominant heat transfer processes for pools with various covers. (1) Visible solar radiation, (2) infrared solar radiation $(<750 \mathrm{~nm})$, (3) infrared solar radiation $(>750 \mathrm{~nm})$, (4) evaporation, (5) heat transfer by conduction and convection from walls of pool, (6) thermal emission into atmosphere, (7) thermal emission from cover into pool and (8) reflection of solar radiation.

For a standard pool with light coloured walls the recommended value of the total absoprtance is $\alpha_{\mathrm{p}}=0.85$ (ISO/TC 180/SC 4 N 140 (1995); Ruiz and Martínez (2010)). The resulting rate equation for the energy balance of an uncovered pool is

$$
C_{\mathrm{p}} \rho V_{\mathrm{p}} \frac{\mathrm{d} T_{\mathrm{p}}}{\mathrm{d} t}=A_{\mathrm{p}}\left[\alpha_{\mathrm{p}} I-\epsilon_{\mathrm{W}} \sigma\left(T_{\mathrm{p}}^{4}-T_{\mathrm{sky}}^{4}\right)-h_{\text {evap }}\left(P_{\mathrm{v}, \mathrm{sat}}\left(T_{\mathrm{p}}\right)-P_{\mathrm{v}, \mathrm{a}}\right)\right] .
$$

However, when a cover is added to a pool, the wavelength dependent transmission of the cover will affect the amount of the solar radiation that is absorbed by both the water and the walls of the pool. The solar gain will also include an indirect transfer of the solar energy that is absorbed by the cover and transferred by thermal radiation and conduction. A diagram showing the energy transfer of solar energy into a pool with a bubble cover is shown in Fig. 9.a). As the cover will be in contact with the water, heat will conduct into the pool and reduce the cover temperature at these contact points. The reduced area of the cover $A_{\mathrm{p}}^{*}$ that is not in contact with the water, and which is at the heated temperature $T_{\mathrm{c}}$, will emit thermal radiation into the pool. Energy from the cover is also lost via convection and thermal radiation(Hahne and Kübler (1994); Ruiz and Martínez (2010); Buonomano et al. (2015)). A simpler model is presented in Fig.9(b) in which the contact between the cover is effectively removed, such that we have made the approximation

$$
A_{\mathrm{p}} \epsilon_{\mathrm{c}} \sigma T_{\mathrm{c}}^{4} \approx A_{\mathrm{p}}^{*} \epsilon_{\mathrm{c}} \sigma T_{\mathrm{c}}^{4}+Q_{\text {cond }} .
$$

Here we have also neglected the contribution of convection which is small compared to solar insolation and thermal radiation(Woolley et al (2011)). The validity of this simplified model will be returned to in Section 7. Using the model in Fig. 9. (b), the rate of solar gain for a pool with a cover will be

$$
Q_{\text {gain }}=A_{p}\left[\alpha_{\mathrm{p}}^{*} I+\epsilon_{\mathrm{c}} \sigma T_{\mathrm{c}}^{4}-\epsilon_{\mathrm{w}} \sigma T_{\mathrm{p}}^{4}\right],
$$

where we introduce the reduced pool absorptance $\alpha_{\mathrm{p}}^{*}$ due to the absorptance of the cover. As the transmitted solar radiation is wavelength dependent, the wavelength dependence of the absorption of water must be considered when determining $\alpha_{\mathrm{p}}^{*}$. We now obtain an equivalent energy balance rate equation for a covered pool

$$
C_{\mathrm{p}} \rho V_{\mathrm{p}} \frac{\mathrm{d} T_{\mathrm{p}}}{\mathrm{d} t}=A_{\mathrm{p}}\left[\alpha_{\mathrm{p}}^{*} I+\epsilon_{\mathrm{c}} \sigma T_{\mathrm{c}}^{4}-\epsilon_{\mathrm{w}} \sigma T_{\mathrm{p}}^{4}\right]
$$




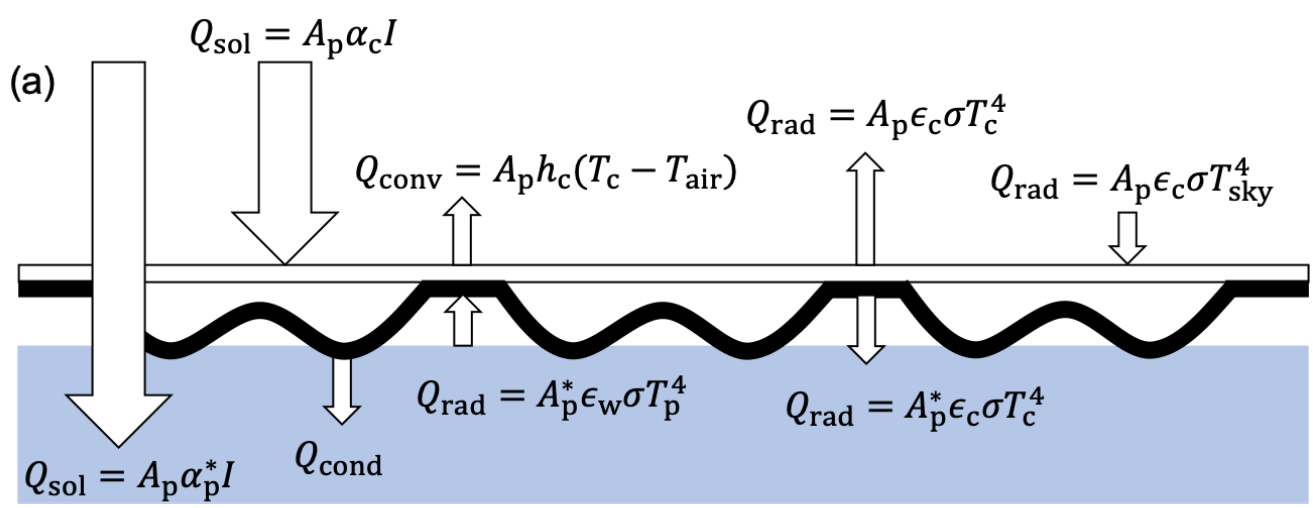

(b) $\quad Q_{\text {sol }}=A_{\mathrm{p}} \alpha_{\mathrm{c}} I$

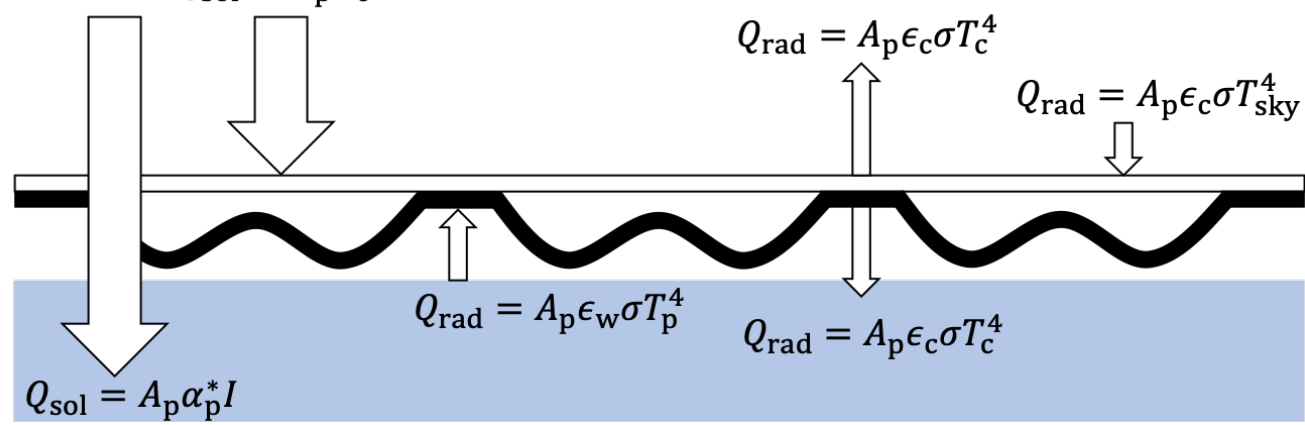

Figure 9: Heat transfer processes for a bubble pool cover (a) including conduction and convection for the realistic system in which the bubble cover is in contact with the water and (b) a simplified version in which the cover is not in contact with the water so that only solar absorption and thermal radiation are considered.

Note that the thermal system of the pool does not include the cover, so that radiative energy transfer is between the pool and the cover, and not the atmosphere. The cover will have a separate energy balance rate equation which includes the gains from the absorption of solar radiation and radiated losses from both the upper and lower surfaces (see Fig.99),

$$
C_{\mathrm{c}} \rho_{\mathrm{c}} V_{\mathrm{c}} \frac{\mathrm{d} T_{\mathrm{c}}}{\mathrm{d} t}=A_{\mathrm{p}}\left[\alpha_{\mathrm{c}} I-2 \epsilon_{\mathrm{c}} \sigma T_{\mathrm{c}}^{4}+\epsilon_{\mathrm{w}} \sigma T_{\mathrm{p}}^{4}+\epsilon_{\mathrm{c}} \sigma T_{\mathrm{sky}}^{4}\right]
$$

Note that the factor of two for the radiative losses is due to the cover radiating from both the upper and lower surfaces.

To compare the measured temperature gains $\Delta T_{\mathrm{p}}$ during the daytime, Eqs. 6,9 and 10 can be integrated over this period to produce equations for the total energies lost and gained. The total daytime energy balance equations for the pool and the cover are

$$
\begin{gathered}
C_{\mathrm{p}} \rho V_{\mathrm{p}} \Delta T_{\mathrm{p}}=A_{\mathrm{p}} \int_{9 \mathrm{am}}^{7 \mathrm{pm}}\left[\alpha_{\mathrm{p}}^{*} I+\epsilon_{\mathrm{c}} \sigma T_{\mathrm{c}}^{4}-\epsilon_{\mathrm{w}} \sigma T_{\mathrm{p}}^{4}\right] \mathrm{d} t \\
\frac{C_{\mathrm{c}} \rho_{\mathrm{c}} V_{\mathrm{c}} \Delta T_{\mathrm{c}}}{A_{\mathrm{p}}}=\int_{9 \mathrm{am}}^{7 \mathrm{pm}}\left[\alpha_{\mathrm{c}} I-2 \epsilon_{\mathrm{c}} \sigma T_{\mathrm{c}}^{4}+\epsilon_{\mathrm{w}} \sigma T_{\mathrm{p}}^{4}+\epsilon_{\mathrm{c}} \sigma T_{\text {sky }}^{4}\right] \mathrm{d} t \approx 0 .
\end{gathered}
$$


The cover has a large area to volume ratio and will radiate energy quickly, such that Eq. 12 is approximated to zero. From Eq. 12 we extract

$$
\int_{9 \mathrm{am}}^{7 \mathrm{pm}} \epsilon_{\mathrm{c}} \sigma T_{\mathrm{c}}^{4}=\frac{1}{2} \int_{9 \mathrm{am}}^{7 \mathrm{pm}}\left[\alpha_{\mathrm{c}} I-\epsilon_{\mathrm{w}} \sigma T_{\mathrm{p}}^{4}-\epsilon_{\mathrm{c}} \sigma T_{\mathrm{sky}}^{4}\right],
$$

which can be substituted into $\mathrm{Eq} 11$ to obtain

$$
C_{\mathrm{p}} \rho V_{\mathrm{p}} \Delta T_{\mathrm{p}}=A_{\mathrm{p}} \int_{9 \mathrm{am}}^{7 \mathrm{pm}}\left[\left(\alpha_{\mathrm{p}}^{*}+\frac{1}{2} \alpha_{\mathrm{c}}\right) I-\frac{1}{2} \epsilon_{\mathrm{w}} \sigma T_{\mathrm{p}}^{4}-\frac{1}{2} \epsilon_{\mathrm{c}} \sigma T_{\text {sky }}^{4}\right] \mathrm{d} t .
$$

This equation relates the pool energy gain $E_{\text {gain }}=C_{\mathrm{p}} \rho V_{\mathrm{p}} \Delta T$ to the total solar energy incident on the surface of the pool $E_{\mathrm{sol}}=A_{\mathrm{p}} \int_{9 \mathrm{am}}^{7 \mathrm{pm}} I \mathrm{~d} t$ and the radiative losses $E_{\mathrm{losses}}$

$$
E_{\text {gain }}=\eta E_{\text {sol }}-E_{\text {losses }} \text {. }
$$

Here we have introduced the cover efficiency $\eta$ which describes the ability of the pool cover to convert solar energy into a pool temperature increase. This cover efficiency is dependent of the transmittance and absorptance of the cover, such that

$$
\eta=\alpha_{\mathrm{p}}^{*}+\beta \alpha_{\mathrm{c}}
$$

where $\beta=0.5$ in our simplified model, which relies on the approximation in Eq. 7 holding true, and in practice it may differ from this value due to the contact between the water and the cover. The physical meaning of $\beta$ is the fraction of energy that is absorbed by the cover which is transferred to the pool.

The radiative energy losses, which are independent of the solar irradiance $I$ are

$$
E_{\text {losses }}=A_{\mathrm{p}} \int_{9 \mathrm{am}}^{7 \mathrm{pm}}\left[\frac{1}{2} \epsilon_{\mathrm{w}} \sigma T_{\mathrm{p}}^{4}-\frac{1}{2} \epsilon_{\mathrm{c}} \sigma T_{\text {sky }}^{4}\right] \mathrm{d} t,
$$

For an uncovered pool the effective efficiency is dependent on the total absorptance of the pool

$$
\eta=\alpha_{\mathrm{p}}
$$

and the total losses are due to evaporation and thermal radiation

$$
E_{\text {losses }}=A_{\mathrm{p}} \int_{9 \mathrm{am}}^{7 \mathrm{pm}}\left[\epsilon_{\mathrm{w}} \sigma\left(T_{\mathrm{p}}^{4}-T_{\mathrm{sky}}^{4}\right)-h_{\mathrm{evap}}\left(P_{\mathrm{v}, \mathrm{sat}}\left(T_{\mathrm{p}}\right)-P_{\mathrm{v}, \mathrm{a}}\right)\right] \mathrm{d} t .
$$

Using the measured wavelength dependent absorption and transmission of the covers with the solar irradiance spectra, Fig. 4, it is possible to determine the predicted efficiencies of each cover using Eq. 16. It is necessary to consider the wavelength dependence of the transmitted light. All light above $750 \mathrm{~nm}$ will be absorbed by the water due to the wavelength dependence on the absorption depth, as shown in Fig. 1. To give a total absorptance of the recommended $\alpha_{\mathrm{p}}=0.85$ (ISO/TC 180/SC $4 \mathrm{~N} 140(1995)$ ) we have taken the total absorptance below $750 \mathrm{~nm}$ as 0.70 and above $750 \mathrm{~nm}$ as fully absorbing. Using the product of the solar irradiance spectra with the absorption and transmission spectra of the covers, we can calculate the reduced pool absorptance $\alpha_{\mathrm{p}}^{*}$ and the cover absorptance $\alpha_{\mathrm{c}}$. From this we can predict the cover efficiencies of each of the covers, using $\beta=0.5$, which are given in Table 4 . 


\begin{tabular}{c|c|c|c|c|c} 
Cover & $T_{(>750)}$ & $T_{(<750)}$ & $\alpha_{\mathrm{c}}$ & $\alpha_{\mathrm{p}}^{*}$ & $\eta$ \\
\hline Transparent & 0.35 & 0.27 & 0.25 & 0.54 & 0.66 \\
Opaque & 0.00 & 0.00 & 0.65 & 0.00 & 0.32 \\
Selective transmission & 0.18 & 0.00 & 0.67 & 0.17 & 0.52
\end{tabular}

Table 4: Predicted solar energy gain efficiencies $\eta$ and reduced pool absorptance $\alpha_{\mathrm{p}}^{*}$, calculated using measured transmittance of solar irradiance above $750 \mathrm{~nm} T_{(>750)}$ and below $750 \mathrm{~nm} T_{(<750)}$, and absorptance of cover $\alpha_{\mathrm{c}}$.

\section{Validation of model}

As the energy losses in Eqs. 17 and 19 are weakly dependent on the solar irradiance, it should be possible to measure a pool cover efficiency by plotting the dependence of the energy gain $E_{\text {gain }}$ against the measured daily solar irradiated energy $E_{\text {sol }}$. This data is plotted in Fig. 10 The predicted linear dependence of Eq. 15 is observed and a least square fit to the data provides the values of $\eta$ and $E_{\text {losses }}$ for each cover which are given in Table 5 The quality of the linear dependence between the solar energy and the pool energy gain is supported by the high $R^{2}$ value of the linear regression, which are all above 0.94 for the covered pools. As was predicted, the transparent cover is the most efficient followed by the selective transmission cover, and opaque cover being least efficient. However, the measured efficiencies for all the covers are higher than the predicted values of the model, in particular, the opaque performs with over $10 \%$ greater efficiency than predicted. This suggests that the value of $\beta=0.5$ is an underestimate and that the fraction of heat absorbed by the cover which is transferred to the pool is greater than $50 \%$. The conduction of heat $Q_{\text {cond }}$ is apparently higher than the approximation in Eq. 7 assumes. To match the measured and predicted efficiencies $\beta$ must be adjusted to $\beta \approx 0.65$ for the transparent cover, $\beta \approx 0.56$ for the selective transmission cover and $\beta \approx 0.68$ for the opaque cover. It can be reasoned that the lower value of $\beta$ for the selective transmission cover is due to the higher water temperature directly beneath the cover, as was observed in Fig. 6. The lower temperature gradient between the cover and the water would reduce conductance, thereby decreasing the fraction of the absorbed energy by the cover from being transferred to the pool. The raises the prospect of increasing the efficiency by increasing the circulation pump duration during daylight hours. It is apparent from this study that more extended testing of the pool cover efficiencies is required to improve our understanding of the thermal processes presented in Fig. 9 (a), the role of the circulation pump and to gain an improved measure of $\beta$.

\begin{tabular}{c|c|c|c|c} 
Cover & $\eta($ exp. $)$ & $\eta$ (predicted) & $E_{\text {loss }}(\mathrm{kWh})$ & $R^{2}$ \\
\hline Uncovered (control) & $0.77 \pm 0.08$ & 0.85 & $58.6 \pm 14.9$ & 0.878 \\
Transparent & $0.71 \pm 0.03$ & 0.66 & $36.7 \pm 6.0$ & 0.981 \\
Opaque & $0.44 \pm 0.03$ & 0.32 & $23.6 \pm 5.6$ & 0.942 \\
Selective Transmission & $0.56 \pm 0.03$ & 0.52 & $18.1 \pm 5.1$ & 0.969
\end{tabular}

Table 5: Measured and predicted cover efficiencies and pool losses for daytime heating for the period of $16^{\text {th }}$ June to $3^{\text {rd }}$ of July 2018 using the full scale test pool facility in the South East of the United Kingdom.

The quality of the fit to the uncovered pool data is lower, with an $R^{2}=0.878$, as it will be more sensitive to variable weather conditions. We also find that the measured equivalent efficiency used for comparing an uncovered pool to a covered pool is lower than would be expected if taken 


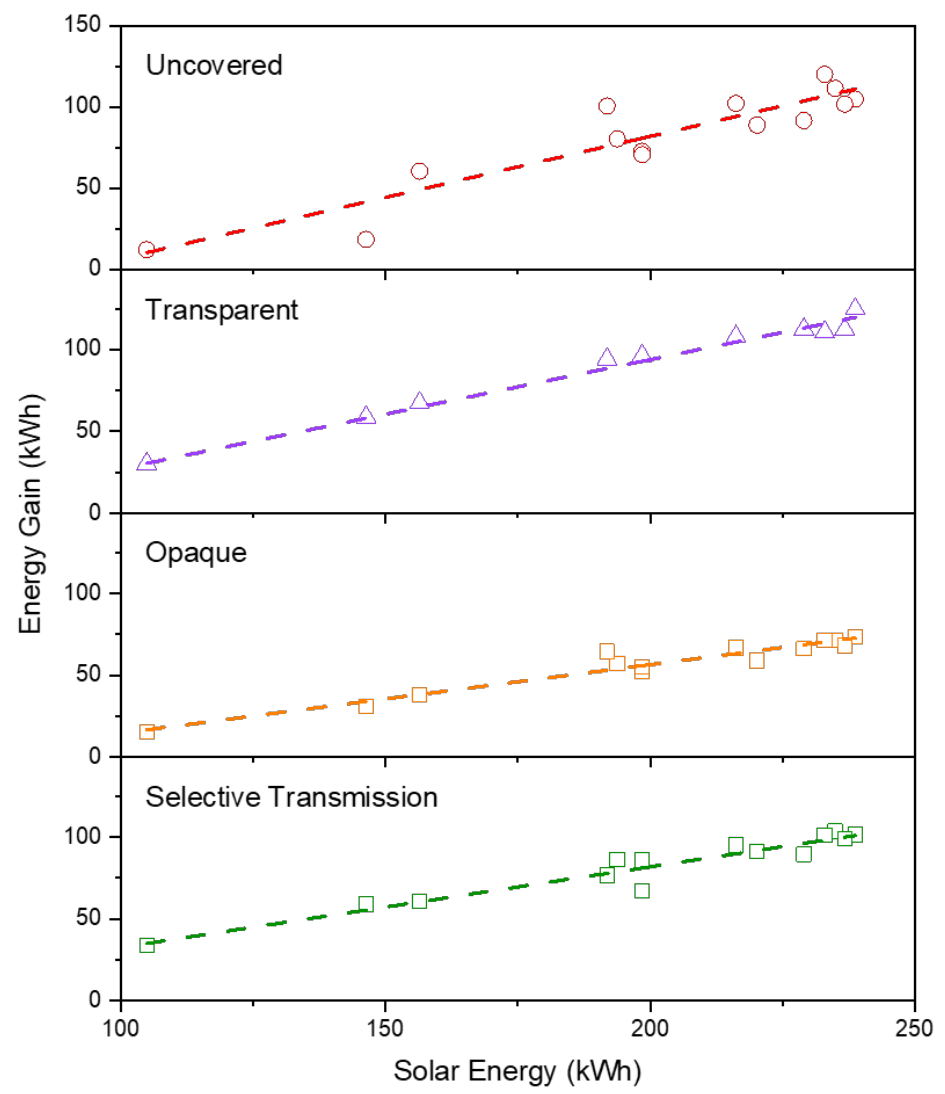

Figure 10: The net energy gained $E_{\text {gain }}$ in the pools in this study as a function of the total solar energy $E_{\text {sol }}$, between 9 am and $7 \mathrm{pm}$ for different covers and an uncovered pool. 
as the total absorptance in Eq. 18 . Our data gives the equivalent efficiency to be $0.77 \pm 0.08$ compared to recommended standard value of absorptance of $\alpha_{\mathrm{p}}=0.85$ (Ruiz and Martínez (2010); ISO/TC 180/SC 4 N 140 (1995)). This suggests the possibility that there are loss mechanisms which are dependent on solar irradiance $I$. An explanation for this can be linked to the measured temperature of the uncovered pool which is found to be uniform with depth, whereas for the covered pools a temperature gradient is observed, as shown in Fig. 6 For the covered pool the water directly beneath the cover will be heated by the warm cover itself, but heating of the water is also by direct absorption of the solar radiation $>750 \mathrm{~nm}$. Evidence for this is seen in Fig. 6 for the selective transmission cover in which the temperature is higher beneath the cover compared to the opaque cover. Here the water is heated by both radiation from the cover and by direct absorption of solar radiation in the near-IR. For an uncovered pool the water near the surface will also be heated by absorption of the near-IR, but a heating of water close to the surface is not observed. This suggests that the energy absorbed close to the surface is dissipated rapidly through evaporation. This loss process would be strongly dependent on $I$ and could contribute losses of up to to $15 \%$ of the total solar irradiation. We note that previous models(Govaer and Zarmi (1981); Ruiz and Martínez (2010); Woolley et al (2011); Hahne and Kübler (1994); Lugo et al. (2019)) assume a uniform pool temperature and may, therefore, inaccurately take into account the dependence of the irradiance on the evaporation losses due to the wavelength selectivity of absorption by water.

As expected, due to evaporation, the uncovered pool has a significant higher energy loss, $E_{\text {losses }}$, which is independent of the solar irradiation. However, there is also an observed variation in the measured $E_{\text {losses }}$ for the three covers despite the pools being designed to be identical. It is currently unclear without further studies whether this variation is due to the differences in the pools or the covers. For this study, the measured difference in $E_{\text {losses }}$ between the transparent and selective transmission cover is $18.1 \pm 8.9 \mathrm{kWh}$, which compares to the average total solar energy gain for the selective transmission cover of $192.3 \pm 41.1 \mathrm{kWh}$. While this difference corresponds to approximately $10 \%$ of the solar gain, it is important to emphasize that this apparent difference is independent of the incident solar energy.

\section{Conclusion}

A covered pool can eliminate evaporative losses which will significantly reduce heat losses during nighttime hours. However, during daylight hours a cover will reduce insolation as the absorptance of the pool from both the water and walls is reduced by the amount of light which is absorbed by the cover. For a transparent cover the reduced absorptance is compensated by eliminating evaporation resulting in a solar efficiency comparable to that of an uncovered pool. For an opaque pool cover, solar heating is solely through heating of the cover which is then radiated and conducted into the pool. This results in a measured $27 \pm 4 \%$ lower solar efficiency compare to the transparent cover. A cover which selectively absorbs the visible region of the solar radiation will inhibit the photosynthesis of algae but allows a proportion of the IR solar radiation to pass through the cover to directly heat the water near the surface. Our measurement of the solar efficiency of the selective transmission cover lies between that of the transparent and opaque covers, with a $12 \pm 4 \%$ higher absolute efficiency than the opaque cover. This compares to an $20 \%$ increase in the absolute efficiency as predicted by the model. The simplified model assumes that the cover is not in direct contact with the water, such that half of the absorbed energy is radiated into the pool. From the comparison between the predicted and observed efficiencies, this fraction of energy that is transferred to pool is higher due to conduction of heat where the cover makes 
contact with the water. To fully understand these energy transfer processes would require a finite element model of the system. In addition, computer fluid dynamic modelling(Doubou (2019)) could provide insight into the role that the circulation pump has on transfer of heat from the cover to the pool. By combining these models with prolonged testing, it is possible that an improved measurement $\beta$ could be obtained.

It is not possible to quantify and compare the chemical consumption of pools with transparent and selective transmission covers as this is strongly dependent on how a pool in maintained. Our own studies(Plastipack (2018) ) have found that the transparent and selective transmission covers used $67 \%$ and $58 \%$ less chemicals, respectively, when a recommended free chlorine level of $3.5 \mathrm{ppm}$ was maintained(WHO (2006)). At these maintained levels of free chlorine, the growth of algae is inhibited and so negates any significant benefit of using a selective transmission cover. However, such a chemical consumption study reflects a perfectly maintained pool without human activity, which would introduce biological matter. In practice, domestic pools are rarely kept in such ideal conditions and with constant high level of free chlorine, with a significant proportion of domestic pool owners electing to purchase an opaque cover in preference to a transparent cover to avoid algae blooms. Evidence of this consumer preference is reflected in current sales of Plastipack's high-performance covers, for which the selective transmission cover (EnergyGuard ${ }^{\mathrm{TM}}$ ) represents a $43.03 \%$ compared to their transparent pool cover $\left(\right.$ SolGuard ${ }^{\mathrm{TM}}$ ) which has a $56.97 \%$ share. This is a clear indication of the products popularity with $\mathrm{m}^{2}$ production of the selective transmittance material growing annually by $20.83 \%$ since the material launched in 2015 . For this sector of consumers who elect for a algae prevention cover, replacing the traditional opaque cover with an alternative selective transmission cover would lead to significant energy savings for heated swimming pools.

\section{Acknowledgements}

This work was funded by Innovate UK through the Knowledge Transfer Partnership (KTP) scheme, grant number 9616.

\section{References}

Aparicio P.J., Ando K., Arnon D.I., 1974 Photochemical activity and components of membrane preparations from bluegreen algae. II. Low-temperature photooxidation of cytochrome b559. Biochimica et Biophysica Acta - Bioenergetics $357,246-251$

APSP, 2015. U.S. swimming pool and hot tub market 2015, Pool \& Hot Tub Alliance.

ASTM, 2012. G173-03(2012) Standard tables for reference solar spectral irradiances: direct normal and hemispherical on $37^{\circ}$ tilted surface. ASTM International. https ://doi.org/10.1520/G0173-03R12

Buonomano A., Luca G.D., Figaj R.D., Vanoli L., 2015. Dynamic simulation and thermo-economic analysis of a photovoltaic/thermal collector heating system for an indoor-outdoor swimming pool. Energy Conversion and Management 99, 176-192

DOE, 2000. Conserving energy and heating your swimming pool with solar energy, National Renewable Energy Laboratory (NREL). https://www.builditsolar.com/Projects/PoolHeating/NRELPoolEnergy28038.pdf

Doubou, A.,2019 Modeling of flow field and heat transfer in a swimming pool. Journal of Mechanical Engineering Research 2 (1) 10

Duysens, L., 1964 Photosynthesis. Progress in Biophysics and Molecular 14, 1-104

Eckardt N.A., 2012. Wavelength dependence of quantum yield for $\mathrm{CO}_{2}$ fixation and photochemical efficiencies of photosystems I and II. The Plant Cell 24 (5) 1711

Emerson R., Lewis C.M., 1943 The dependence of the quantum yield of chlorella photosynthesis on wave lenghth of light. American Journal of Botany. 30, 165-178

Goedheer J.C., 1969 Energy transfer from carotenoids to chlorophyll in blue-green, red and green algae and greening bean leaves. Biochimica et Biophysica Acta - Bioenergetics 172 (2), 252-265 
Govaer D., Zarmi Y., 1981 Analytical evaluation of direct solar heating of swimming pools. Solar Energy 27 (6), 529-553

Hahne E., Kübler R., 1994. Monitoring and simulation of the thermal performance of solar heated outdoor swimming pools. Solar Energy 53 (1), 9-19

Hale G.M., Querry M.R., 1973. Optical constants of water in the $200 \mathrm{~nm}$ to $200 \mu \mathrm{m}$ wavelength region. Appl. Opt. (3) $555-563$

IEASTSUS47, 2018. Private weather station - Baldslow, U.K. https://www . wunderground. com/dashboard/pws/ IEASTSUS47/graph/2018-07-15/2018-07-15/daily

ISO/TC 180/SC 4 N 140, 1995. Solar energy - heating systems for swimming pools - design and installation.

Kirk J.T.O., 1994. Light and Photosynthesis in Aquatic Ecosystems, second ed. Cambridge University Press.

Lugo S.,Morales L.I., Best R., Gómez V.H., García-Valladares., 2019 Numerical simulation and experimental validation of an outdoor-swimming-pool solar heating system in warm climates. Solar Energy 189, 45-56

Muleta M., 2015. Effectiveness of pool covers to reduce evaporation from swimming pools. National Plasters Council, https://www.aquatechpoolsystems.com/wp-content/uploads/2016/01/ Evaporation-Study-on-pool-covers.pdf Last accessed 17/01/2020.

Nowell, L.H., 1992. Photolysis of aqueous chlorine at sunlight and ultraviolet wavelengths-II. Hydroxyl radical production. Water Research 26 (5), 599-605.

Plastipack Ltd, 2018. Unpublished study of chlorine consumption comparing transparent and selective transmission covers. Data provided in Research Materials

Ruiz E., Martínez P.J., 2010. Analysis of an open-air swimming pool solar heating system by using an experimentally validated TRNSYS model. Solar Energy 84 (1), 116-123.

Sweers H.E., 1976. A nomogram to estimate the heat-exchange coefficient at the air-water interface as a function of wind speed and temperature; a critical survey of some literature. Journal of Hydrology 30 (4), 375-401.

Walton G.N., 1983. Thermal analysis research program reference manual. National Bureau of Standards, 83-2655

WHO, 2006. Guidelines for safe recreational water environments, Volume 2: Swimming pools and similar environments. World Health Organization https://www.who.int/water_sanitation_health/bathing/srwe2full.pdf

Woolley J., Harrington C. Modera M., 2011 Swimming pools as heat sinks for air conditioners:Model design and experimental validation for natural thermal behavior of the pool. Building and Environment 46 (1) 187-195

Yellott J.I., 1963. Swimming pool cover for collection or reflection of solar heat. U.S. Patent 3,072,920

Yokono M., Murakami A., Akimoto S., 2011 Excitation energy transfer between photosystem II and photosystem I in red algae: Larger amounts of phycobilisome enhance spillover. Biochimica et https://www.overleaf.com/6239918899cztkpbvqtrynBiophysica Acta - Bioenergetics 1807 (7), 847-853 